\title{
Effective Utilization of Flue Gas from Titanium Dioxide Production Plant
}

\author{
${ }^{* \mathrm{a}}$ Sukanya Karuppannan, ${ }^{* \mathrm{~b}}$ Amruth Chandran, ${ }^{* \mathrm{c}}$ Faxen Francis, ${ }^{* \mathrm{~d}}$ Javith \\ Khan, ${ }^{* \mathrm{e}}$ Dhinakaran \\ ${ }^{* a}$ Assistant Professor, Department of Petrochemical Engineering, JCT college of Engineering and Technology \\ ${ }^{* b, c, d, e}$ Department of Petrochemical Engineering, JCT college of Engineering and Technology
}

\begin{abstract}
The calciner uses furnace oil as its fuel. The flue gases coming from the calciner has a high thermal energy. This work is done to effectively utilize the thermal energy produced and hence to reduce the fuel consumption. By utilizing the heat energy of flue gases, the $\mathrm{TiO}_{2}$ slurry can be preheated using a heat exchanger. This preheating can reduce the total amount of the furnace oil used in the combustion chamber. Also by effectively utilizing the remaining heat of the gases using another heat exchanger, the furnace oil can be preheated which in turn eliminates the use of heating coil. Thus the efficiency of the plant can be improved by this technique.
\end{abstract}

Keywords: Titanium Dioxide production, Flue Gas utilization, Heat Exchanger, Electrostatic Precipitator, (ESP) Induced Draught Fan, Rutile and Anatase

\section{Introduction}

Titanium dioxide ${ }^{[1]}$ also known as titanium(IV) oxide or titania, is the naturally occurring oxide of titanium, chemical formula $\mathrm{TiO}_{2}$ when used as a pigment is called titanium white, Pigment White 6 (PW6). It is generally sourced from ilmenite which is an ore, rutile and anatase. The flue gases present within the titanium dioxide production is to be utilized effectively by these methods. A flue gas ${ }^{[2]}$ is usually composed of Carbon dioxide and water vapour as well as nitrogen and excess oxygen remaining from the intake combustion air. It also contains a small percentage of pollutants such as particulate matter, carbon monoxide, nitrogen oxides and sulfur oxides. The overall world production ${ }^{[9]}$ in 2014 exceeded 9 million metric tons.

\section{Present Methodology:}

\section{Materials And Methods}

A Major Proportion of the Present Methodology is first started by combustion. Combustion ${ }^{[2]}$ takes place inside the combustion chamber where furnace oil is sprayed and cold air is passed through the blower. The temperature of the calciner at the combustion chamber side is $1200^{\circ} \mathrm{C}$. At present, a flue gas ${ }^{[9]}$ at $400^{\circ} \mathrm{C}$ is esent out of the calciner. This high energy of the flue gas is not employed effectively for any useful purposes. This flue gases contains many harmful impurities which cannot be directly exhausted to the atmosphere. Hence an electrostatic precipitator (ESP) is used. This ESP absorbs ${ }^{[10]}$ all the harmful gases before being passed through the chimney. But ESP cannot withstand temperature higher than $100^{\circ} \mathrm{C}$. As the electrode inside ESP metal at temperature above $110^{\circ} \mathrm{C}$, therefore it is highly essential to bring down the temp of flue gases to safe limits, so that ESP works smoothly. To cool the flue gases from $400^{\circ} \mathrm{C}$ to $100^{\circ} \mathrm{C}$, a cooling tower is used. The amount of water used by this cooling tower is $500 \mathrm{kl} / \mathrm{day}$ and the power consumption of the motor used is $25 \mathrm{hp}$. The Major components of this present methodology consists of cooling tower, electrostatic precipitator and the induced draught fan. The cooling tower has a height of $10 \mathrm{~m}$. After combustion the flue gases at a temp of about $1200^{\circ} \mathrm{C}$ oxidize the hydrated titanium given as feed to the calciner and take the gases contained in the feed along with it. The Flue gases ${ }^{[3]}$ are given out through an outlet pipe and enter the cooling water tower through the bottom. Also there is a provision for water spray from the top. Most of the particles carried by the gas dissolves in the water and i takeout. The rest of the gases goes up from the cooling tower and is supplied to the ESP by means of a pipe provided at the top of the cooling tower. Acid resisting brick line is provided inside the cooling tower.The ESP consists of two chamber; one chamber consists of lead tubes containing electrodes for attracting remaining particles contained in the gas coming from the cooling tower. The gas from the cooling tower enters the EXP at the middle shell and reaches the bottom and then move upward through lead tubes. Electrodes with high voltage DC conneted to it, kept inside of the tubes attract the oppositely charged particles. Water is also made to flow through the inside of the tubes wetting the electrodes, thereby washing away the particles attracted by the electrode. Electrode are kept hanging inside the tubes without touching the side of the tubes. The gas remaining is sucked out and exhausted through the exhaust tower with the help of ID fan. The ID fan consists ${ }^{[8]}$ 
of an impeller connected to a motor which has a power of 40hp at 1440rpm. The fan sucks the flue gases from the calciner through the calciner tower, ESP and given out through the exhaust tower.

\section{Proposed Methodology: \\ Combustion Air Pre-Heating:}

Instead of supplying cold air inside the combustion chamber, hot air has been used. This has been done by creating an extra chamber outside the combustion chamber. This chamber is made of ebonite and its diameter is 10inches more than the diameter of the combustion chamber. Now the air is supplied inside the ebonite chamber, which absorbs the heat of combustion chamber. This hot gas is utilized for combustion. It has been found out from the fuel flow meter that by using hot air for combustion, the amount of fuel combusted can be reduced from 9000 liters/day to 7830 liters/day. By incorporating this method ${ }^{[5]}$ the surface temperature of the combustion chamber can also be reduced. " $13 \%$ of fuel has been saved by this preheating method"

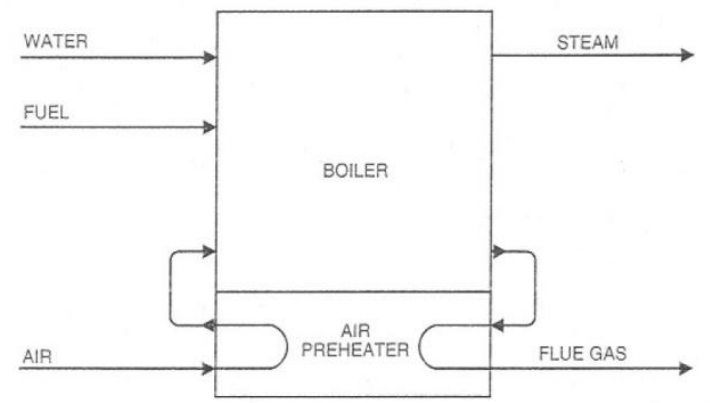

Fig.1.Combustion Air Preheater

Combustion chamber ${ }^{[2]}$ is a chamber connected to one end of the calciner where combustion takes place. It is trolley mounted and oriented horizontally. At present the fuel used is furnace oil. It has an outside diameter of $2.5 \mathrm{~m}$ and length about $4 \mathrm{~m}$. It is provided with a brick lining at the inside. To the combustion chamber the primary and secondary blowers are connected. At the one end of combustion chamber, burner is fitted. Oil from the oil pump and atomizing air from atomizing air from atomizing air blower reaches at combustion chamber through the burner. At the burner it gets mixed and as soon as it reaches the combustion chamber through the burner. At the burner it gets mixed and as soon as it reaches the combustion is provided by the primary and secondary air blowers. The temperature of the combustion chamber is high as $1200^{\circ} \mathrm{C}$.The function ${ }^{[4]}$ of atomizing air blower is to atomize the furnace oil that is fed to the burner. It provides sufficient air pressure to get complete combustion of furnace oil. The power of motor used in this is $10 \mathrm{hp}$ and has an rpm of 2880. The primary blower is used to transfer the heat towards the feed end of the calciner. It uses a $40 \mathrm{hp}$ motor with an rpm of 2946. It is connected to the combustion chamber. It transfers the heat to the half length of the calciner kiln. The secondary blower does the same purpose of the primary air blower. It transfers heat to the feed end. The motor used in the blower has an rpm 1440, and power of $10 \mathrm{hp}$. Then the burners are used to produce fire in the calciner. Furnace oil is used as the fuel in the burner. Atomizing air blower and furnace oil is connected to the burner. The fuel flow is controlled with the help of a control valve to the burner. Fuel pump uses a $2 \mathrm{hp}$ motor. A pumping pressure between 50-60 psi is required to get required heat.

\section{Result \& Discussion}

From the above process by effectively utilizing the remaining heat of the gases using another heat exchanger, the furnace oil ${ }^{7]}$ can be preheated, eliminates the heating coil. Thus the efficiency of the plant can be improved. Here, it is difficult to achieve the tangential flow due to the weight of the slurry. But, that can be achieved by using a pumping mechanism. Also by using an ultra high temperature plastic as a coating material for the preheater, due to its non sticky nature, choking can be avoided as choking was considered to be an important drawback. The process of calcination is used to remove water content of slurry to produce dry Titanium Dioxide. At the present condition the total amount of fuel used is not effectively utilized. Only $1 / 3^{\text {rd }}$ is utilized and the remaining amount of fuel is wasted. This results in heavy heat loss. Hence it is decided to find out a method for effective utilization of fuel in the calciner.

\section{Conclusion}

The methods for effective utilization of fuel in the calciner are done by using preheated air for combustion. Combustion to produce energy can be a form of recycling.Therefore; the proposed concept could become an attractive option for efficiency improvements. 


\section{Reference}

[1]. Tjatjopoulos, G.J. and Vasalos, I.A, Feasibility analysis of Ternary Feed Mixtures of Methane with oxygen, steam, and carbon dioxide for the production of Methanol Synthesis Gas.Ind.Eng.Chem.Res.,1998,37,1410-1421.

[2]. Inui T.,Saigo k.,Fujii Y., and Fujioka K. Catalytic combustion of Natural Gas as the Role of On-site Heat Supply in Rapid Catalytic $\mathrm{CO}_{2}-\mathrm{H}_{2} \mathrm{O}$ Reforming Methane.Catal today,, 1995,26(3-4)295-302.

[3]. Choudary, V.R., and Rajput A.M.Simultaneously Carbon dioxide and Steam Reforming of Methane to Syngas over NiO/MgO/SA5205 in presence and absence of Oxygen.Appl. Catal. A;Gen.,1998,168,33-46

[4]. Choudary,V.R.;Uphade,B.S.,Mamman,Carbon dioxide and Steam Reforming of Methane to Syngas over Nio-Cao Catalyst.Ind.Eng,Chem,Res,1996,35,3934-3939.

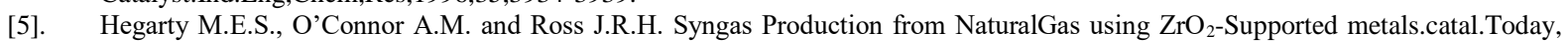
1998, 429(3), 225-232

[6]. Song, C., Srinivas, S.T.Pan, W. and Sun, L.Technical Program, $17^{\text {th }}$ North American Catalysis society meeting, Toronto, Canada, June 3-8, 2001.

[7]. Song, C. A Proposed Concept for $\mathrm{CO}_{2}$-Based Tri-generation of Chemicals,Fuels and Electricity.Am.Chem.prepr.,2000,45(1),159163

[8]. DOE/FETC Vision 21 program Plan-Clean Energy Plants for the $21^{\text {st }}$ Century .Federal Energy Technology Center, Office of Fossil Energy, U.S. DOE, 1999C.

[9]. Effective utilization of flue gases in raceway reactor-pawlowski.A,et al.,Bioresour Technol.,(2014) 45-47

[10]. Electrospun metal oxide titaniumdioxide nanofibers for elemental mercury removal from flue gas,yuan yuan,yongchun zhao, hailong li, yang li, xiang gao, Journal of hazardous materials,(2012);427-435

[11]. U.S.Environmental protection agency,air toxics standards for utilities, http://www.epa.gov/ttn/atw/utility/utilitypg.html (2011)

[12]. Preparation and characterization of the titaniumdioxide/polymer complex nanomaterial,B.T.Su,X.H.Liu et al.,mater.sci.eng.A.349 (2003) 59-62 